\title{
Interferon alfa treatment for Siögren's syndrome associated neuropathy
}

\author{
S Yamada, K Mori, K Matsuo, A Inukai, Y Kawagashira, G Sobue
}

J Neurol Neurosurg Psychiatry 2005;76:576-578. doi: 10.1136/jnnp.2004.049502

Treatment response to interferon alfa (IFN $\alpha$ ) is described in three consecutive cases of two forms of Siögren's syndrome associated neuropathy (SSN)-two with sensory ataxic ganglionopathy and one with sensorimotor neuropathy with demyelinating features. All responded well to IFN $\alpha$ in terms of neuropathic symptoms, sicca symptoms, antibody titres, and findings in salivary gland biopsy specimens. IFN $\alpha$ thus showed promise in treating both SSN and the underlying Siögren's syndrome.

A lthough peripheral neuropathy is the most common extraglandular manifestation of Sjögren's syndrome, treatment of this complication is not well established. ${ }^{\prime}$ Interferon alfa (IFN $\alpha$ ) administration has been reported to alleviate Sjögren's syndrome associated sicca symptoms, as evidenced by increased salivary flow, and also to reduce histologically evident disease activity. ${ }^{2}$ So far, the effects of IFN $\alpha$ on any extraglandular complications such as Sjögren's syndrome associated neuropathy (SSN) have not been reported. We describe the therapeutic effects of IFN $\alpha$ in three consecutive patients with two forms of SSN-two with sensory ataxic ganglionopathy and one with sensorimotor neuropathy.

\section{CASE PRESENTATIONS}

\section{Patient 1}

An otherwise healthy 46 year old man developed dysaesthesia which first involved the left foot and then progressed to affect the right foot and left hand in September 1997, finally progressing to his right foot and left hand. Over the next three years, the level of dysaesthesia gradually ascended to involve both thighs, and difficulty in walking led to hospital admission under our care. On admission, sensory examination revealed profoundly reduced vibratory and proprioceptive sensation affecting mainly the lower limbs, with slight loss of pain and temperature sensation. The heel to knee test showed marked dysmetria in both legs, particularly with the eyes closed. Deep tendon reflexes were absent in all limbs. Muscle strength was slightly decreased in the lower limbs. The patient could barely walk unassisted because of severe ataxia (sensory ataxia scale 5, table 1). ${ }^{3}$ Romberg's test was strongly positive. No signs of autonomic dysfunction were evident. Routine haematological examination yielded normal results. Anti-SS-A/SS-B antibodies were positive at 42.0/18.0, respectively (by enzyme linked immunosorbent assay (ELISA); normal values are SS-A/SS-B <10.0/15.0). In cerebrospinal fluid (CSF), protein content was modestly raised $(60 \mathrm{mg} / \mathrm{dl})$, and the cell count was normal. Results of nerve conduction studies were normal in the upper limbs, but in the lower limbs the sensory nerve action potential (SNAP) in the sural nerve showed reduced amplitude $(0.2 \mu \mathrm{V})$ with normal conduction velocity $(\mathrm{CV}, 48 \mathrm{~m} / \mathrm{s})$. Other nerve conduction study findings, as well as statokinesigraphy results ${ }^{4}$, are summarised in table 1 . Somatosensory evoked potentials (SEP) could not be elicited by lower limb stimulation. Cervical spinal cord magnetic resonance imaging (MRI) on $\mathrm{T}^{*}$ weighted images showed abnormal high intensity areas in the dorsal columns, reflecting the sensory ataxic ganglionopathy. ${ }^{5}$ Findings on sural nerve biopsy were decreased numbers of large myelinated fibres, axonal degeneration without axonal sprouting, endoneurial oedema, and no evidence of vasculitis. The patient was treated with prednisolone (30 to $10 \mathrm{mg} /$ day), cyclosporin ( $100 \mathrm{mg} /$ day), and plasmapheresis, but without improvement. In August 2001, intravenous immunoglobulin treatment (IVIG) was given $(0.4 \mathrm{~g} / \mathrm{kg}$ for five days). After this treatment, dysaesthesias in the legs and left hand were reduced, and the patient was able to walk with less effort. However, he required repeated five day courses of IVIG every three to four weeks to halt the progression of the disease. Sicca symptoms developed and Schirmer's test gave a positive result $(3 \mathrm{~mm} /$ $5 \mathrm{~mm}$, right/left). A labial salivary gland biopsy specimen showed marked lymphocytic infiltration and acinar cell destruction, graded as 3 by Daniels focus scores. ${ }^{6}$

In November 2003, IFN $\alpha$ treatment was initiated (3 MIU/ day, three times weekly). Over the next two months, the patient showed dramatic improvement; dysaesthesias nearly disappeared and he was able to walk without effort. Nerve conduction studies revealed improvement of SNAP amplitude in the sural nerve (table 1). Statokinesigraphy also showed significant improvement $(\mathrm{p}<0.01$, table 1$)$. Sicca symptoms resolved and lacrimation increased (Schirmer's test; $18 \mathrm{~mm} /$ $14 \mathrm{~mm}$, right/left). Anti-SS-A/SS-B antibody titres fell to the normal range (9.1/9.2 respectively) and a follow up labial salivary gland biopsy showed fewer infiltrating lymphocytes graded as 2. ${ }^{6}$ The clinical and therapeutic time course of patient 1 is summarised in fig $1 \mathrm{~A}$.

\section{Patient 2}

A 67 year old woman with Sjögren's syndrome developed sensory ataxic ganglionopathy over 14 years. She did not respond to prednisolone, cyclophosphamide, or plasmapheresis and required frequent (every two or three month) IVIG therapy to maintain her activities of daily living, as for patient 1. In December 2003, she was admitted to our department and treated with IFN $\alpha$ ( 3 MIU/day, three times weekly). After the initiation of IFN $\alpha$, she had marked improvement in vibratory and proprioceptive sensation, leading to improvement of her activities of daily living. Nerve conduction studies showed improvement in SNAP amplitude in the sural nerve and statokinesigraphy demonstrated significantly

Abbreviations: CV, conduction velocity; IFN $\alpha$, interferon alfa; IVIG, intravenous immunoglobulin; SEP, somatosensory evoked potentials; SNAP, sensory nerve action potential; SSA/SSB, Sjögren's syndrome associated antibody A and B; SSN, Siögren's syndrome associated neuropathy 
Table 1 Nerve conduction studies, statokinesigraphy, Rankin scale, and status of Sjögren's syndrome before and after interferon alfa treatment

\begin{tabular}{|c|c|c|c|c|c|c|}
\hline \multirow[b]{2}{*}{ Variable } & \multicolumn{2}{|l|}{ Patient 1} & \multicolumn{2}{|l|}{ Patient 2} & \multicolumn{2}{|l|}{ Patient 3} \\
\hline & Before Rx & After $\mathrm{Rx}$ & Before Rx & After $\mathrm{Rx}$ & Before $\mathbf{R x}$ & After $\mathbf{R x}$ \\
\hline \multicolumn{7}{|l|}{ Motor conduction } \\
\hline $\mathrm{R}$ median amplitude $(\mathrm{mV}) / \mathrm{CV}(\mathrm{m} / \mathrm{s})$ & $4.8 / 56$ & $4.7 / 58$ & $10.6 / 55$ & $12.9 / 53$ & $3.1 / 35$ & $3.8 / 42$ \\
\hline R ulnar amplitude $(\mathrm{mV}) / \mathrm{CV}(\mathrm{m} / \mathrm{s})$ & $7.8 / 47$ & $8.0 / 48$ & $7.2 / 44$ & $7.0 / 47$ & $10.5 / 38$ & $11.6 / 40$ \\
\hline R tibial amplitude $(\mathrm{mV}) / \mathrm{CV}(\mathrm{m} / \mathrm{s})$ & $5.8 / 43$ & $6.8 / 46$ & $5.2 / 31$ & $4.9 / 31$ & $12.1 / 28^{*}$ & $11.6 / 35$ \\
\hline \multicolumn{7}{|l|}{ Sensory conduction } \\
\hline $\mathrm{R}$ median amplitude $(\mu \mathrm{V}) / \mathrm{CV}(\mathrm{m} / \mathrm{s})$ & $11.6 / 55$ & $11.6 / 52$ & $39.8 / 45$ & $41.3 / 40$ & $10.3 / 37$ & $12.4 / 36$ \\
\hline R ulnar amplitude $(\mu \mathrm{V}) / \mathrm{CV}(\mathrm{m} / \mathrm{s})$ & $13.0 / 51$ & $14.0 / 48$ & $11.2 / 40$ & $15.8 / 48$ & $11.6 / 22$ & $12.7 / 32$ \\
\hline R sural amplitude $(\mu \mathrm{V}) / \mathrm{CV}(\mathrm{m} / \mathrm{s})$ & $0.2 / 48$ & $8.9 / 45$ & $1.2 / 51$ & $10.6 / 48$ & $12.9 / 40$ & $10.6 / 48$ \\
\hline Statokinesigram $(\mathrm{cm}) \dagger$ & $\begin{array}{l}217.7(28.3) / \\
346.3(62.9)\end{array}$ & $\begin{array}{l}72.5(10.8) / \\
195.8(12.5)\end{array}$ & $\begin{array}{l}125.5(12.9) / \\
\text { NP }\end{array}$ & $\begin{array}{l}7.79(0.64) / \\
\text { NP }\end{array}$ & NP & NP \\
\hline Modified Rankin scaleł & $2-3$ & 1 & $2-3$ & 1 & $2-3$ & 0 \\
\hline Sensory ataxia scale§ & 5 & 3 & 5 & 2 & 2 & 1 \\
\hline Positive items for SS & $\mathrm{I}, \mathrm{II}, \mathrm{III}, \mathrm{IV}, \mathrm{VI}$ & $\|$ & $\mathrm{I}, \mathrm{II}, \mathrm{IV}, \mathrm{VI}$ & II, IV & $\mathrm{I}, \mathrm{II}, \mathrm{IV}, \mathrm{VI}$ & none \\
\hline Anti-SS-A/SS-B antibody titres ${ }^{* *}$ & $42.0 / 18.0$ & $9.1 / 9.2$ & $47.1 / 32.0$ & $8.8 / 9.3$ & $47.0 / 8.2$ & $3.1 / 2.6$ \\
\hline Schirmer's test (right/leff, mm) & $3 / 5$ & $18 / 14$ & $12 / 16$ & $19 / 22$ & $16 / 9$ & $14 / 35$ \\
\hline Daniels focus score (grade/focus)t† & $3 / 0$ & $2 / 0$ & $4 / 3$ & $3 / 0$ & $4 / 3$ & $2 / 0$ \\
\hline
\end{tabular}

*Temporal dispersion was observed.

†Statokinesigram ${ }^{4}$ : total movement length of the gravity centre with eyes opened/closed during 30 seconds, $n=6$ (mean (SD)).

$\ddagger$ Modified Rankin scale: 0 , no symptoms at all; 1 , no significant disability, able to carry out all usual duties and activities; 2 , slight disability, unable to carry out delicate tasks but able to look after own affairs without assistance; 3 , moderate disability, requiring some help, but able to walk without assistance; 4 , moderately severe disability, unable to walk without assistance and unable to attend to own bodily needs without assistance; 5 , severe disability, bedridden.

\$Sensory ataxia scale ${ }^{3}: 0$, normal ability to stand on one foot with eyes closed; 1 , stands/walks normally with eyes closed; 2 , stands/walks with minor swaying with eyes closed but normally with eyes open; 3 , stands/walks with some swaying with eyes open; 4 , stands/walks on a large base with eyes open; 5 , standing/ walking impossible without support.

-Items in the revised Euro-criteria for Sjögren's syndrome are: I, ocular symptoms; II, oral symptoms; III, ocular signs (positive Schirmer's test); IV, histopathological features; $\mathrm{V}$, salivary gland involvement; $\mathrm{VI}$, autoantibodies to SS-A or SS-B.

${ }_{* *}$ Normative value for anti-SS-A/SS-B antibody titres in ELISA are $<10 /<15$, respectively.

††Daniels focus score ${ }^{6}$ : grade is based on infiltrate of lymphocytes, plasma cells, and macrophages per $4 \mathrm{~mm}^{2}$ area of salivary tissue: grade 0, absent; grade 1, slight infiltrate; grade 2, moderate infiltrate, less than one focus; grade 3, one focus; grade 4, two or more foci. Focus score (extension of grade 4), 2-10: number of foci of $>50$ mononuclear cells per $4 \mathrm{~mm}^{2}$ area of salivary gland.

$\mathrm{NP}$, not performed; Rx, treatment with IFN $\alpha$.

improved balance, as in patient 1 . Her clinical and neurophysiological features are summarised in fig $1 \mathrm{~B}$ and table 1.

\section{Patient 3}

A 45 year old woman with a history of hypothyroidism developed progressive weakness and dysaesthesias in both feet in December 2000. Within six weeks she became unable to walk, and was admitted to a hospital affiliated with Nagoya University. Neurological examination indicated mild weakness, mild loss of both positional and vibratory sensation, and slight loss of pain and temperature sensation involving all limbs, especially distally. Deep tendon reflexes were absent in all limbs. No autonomic symptoms were present. Routine haematological findings were normal. Serum anti-SS-A antibody was positive while anti-SS-B antibody was negative (anti-SS-A/SS-B 47.0/8.2, respectively). CSF protein content was raised $(124 \mathrm{mg} / \mathrm{dl})$, with a normal cell count. A labial salivary gland biopsy specimen showed marked lymphocytic infiltration graded as 4 (focus $3) .{ }^{6}$ Nerve conduction studies showed a symmetrical sensorimotor polyneuropathy with reduced conduction velocities and the presence of temporal dispersion (table 1). The patient was treated with prednisolone (60 mg/day), cyclosporin ( 100 $\mathrm{mg} /$ day), and cyclophosphamide ( $100 \mathrm{mg} /$ day) with no effect on the progression of disability. Plasmapheresis resulted in a slight improvement in activities of daily living lasting less than two weeks. After IVIG treatment ( $0.4 \mathrm{~g} / \mathrm{kg}$ for five days), she had marked clinical improvement; dysaesthesias and weakness in all limbs gradually lessened, and she could walk without support. However, there were multiple relapses during the next two years. Beginning in April 2002, intervals between relapses shortened and sicca symptoms developed. A sural nerve biopsy specimen revealed subperineurial and endoneurial oedema with evidence of remyelination.
In June 2003, IFN $\alpha$ treatment (3 MIU/day, three times weekly) was started. Within 30 days, dysaesthesias and weakness nearly disappeared. After eight weeks, nerve conduction studies showed slight improvement (table 1). On follow up labial salivary gland biopsy specimen there were significantly fewer infiltrating lymphocytes graded as $2,{ }^{6}$ and sicca symptoms resolved. The serum anti-SS-A/SS-B antibody titres also fell to within the normal range (3.1/2.6, respectively). The clinical and therapeutic time course of patient 3 is summarised in fig $\mathrm{lC}$.

\section{DISCUSSION}

Sjögren's syndrome associated neuropathy includes a wide spectrum of manifestations such as sensory ataxic ganglionopathy, sensorimotor polyneuropathy, demyelinating polyradiculoneuropathy, multiple cranial neuropathy, and vasculitic neuropathy. ${ }^{7}$

Sensory ataxic ganglionopathy often develops in patients with Sjögren's syndrome and is characterised by severe impairment of kinaesthetic sensation with no obvious motor involvement. ${ }^{8}$ This form of neuropathy is chronic and progressive, occasionally responding to treatment with IVIG. ${ }^{9}$ In our patients with this type (patients 1 and 2), IVIG treatment partially lessened the neuropathic symptoms, but repeated courses were needed and they did not improve the overall status of the Sjögren's syndrome.

Previous reports have indicated that demyelinating polyradiculoneuropathy sometimes develops in patients with Sjögren's syndrome, and have shown that the concurrence of Sjögren's syndrome and demyelinating polyradiculoneuropathy is not coincidental but reflects a common underlying immunological derangement. ${ }^{6}$ We diagnosed patient 3 as having SSN with mainly demyelinating features (demyelinating polyradiculoneuropathy), on the basis of the clinical 


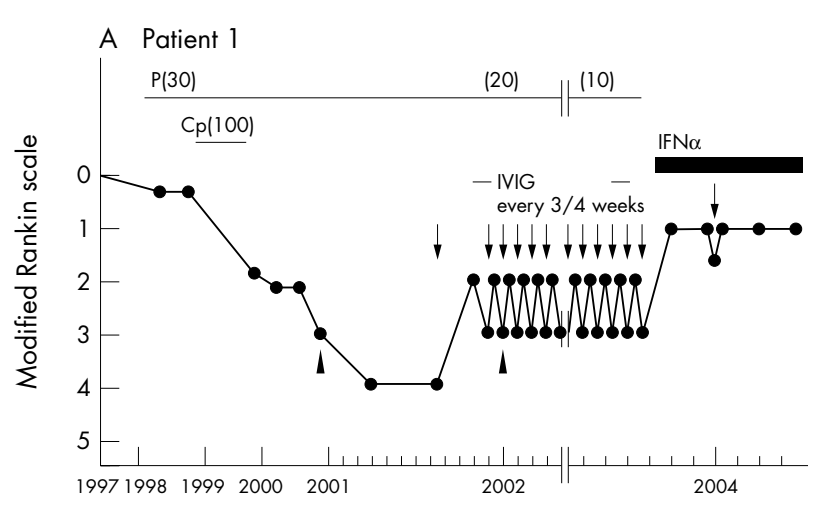

B Patient 2
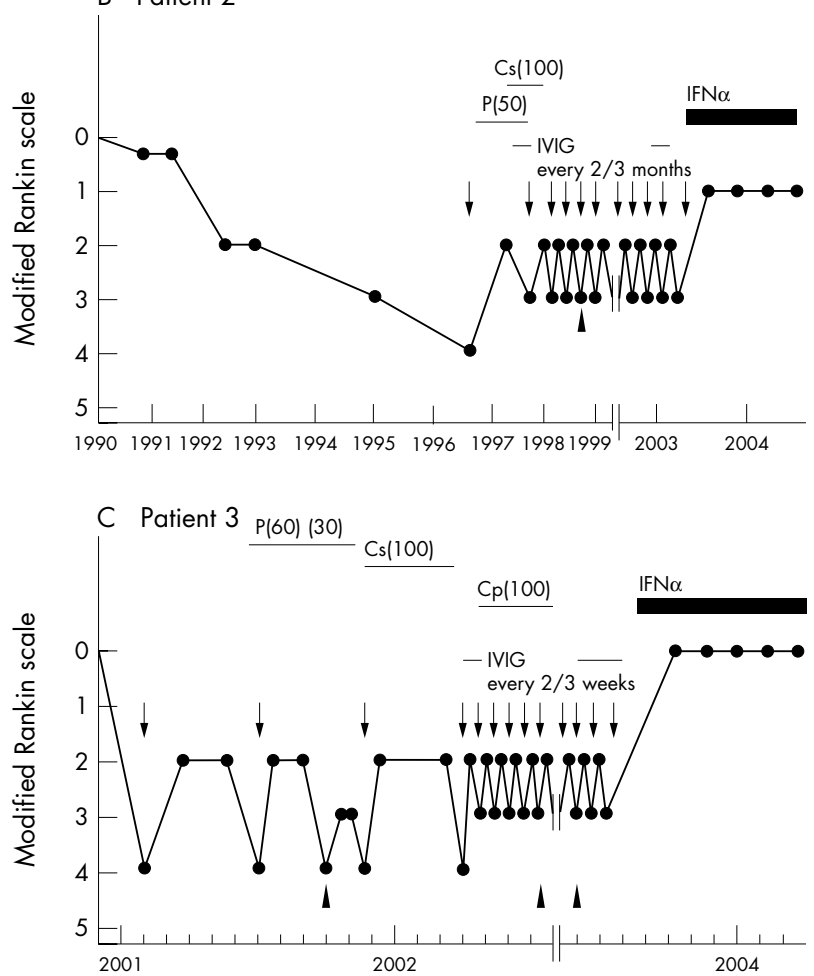

Figure 1 Clinical course of patient $1(A)$, patient $2(B)$, and patient 3 (C). All three patients needed repeated doses of intravenous immunoglobulin (IVIG) treatment to maintain their activities of daily living. After the initiation of interferon alfa (IFN $\alpha$ ), their symptoms were markedly improved. Arrows = episodes of IVIG treatment, $0.4 \mathrm{~g} / \mathrm{kg}$ for five days; arrowheads = plasmapheresis. $\mathrm{Cp}$, cyclophosphamide; $\mathrm{Cs}$, cyclosporin; P, prednisolone.

features and the findings on nerve conduction studies: reduced conduction velocities, presence of temporal dispersion, and histopathological evidence of remyelination.

Use of IFN $\alpha$ for Sjögren's syndrome first was described in 1993. ${ }^{10}$ Since then, orally administered IFN $\alpha$ has been reported to be effective for the sicca symptoms of this condition, resulting in significant increases in salivary gland function and histological improvement in specimens from minor salivary glands. ${ }^{2}$

Before treatment with IFN $\alpha$, all of our three patients had positive serum anti-SS-A/SS-B antibodies, characteristic salivary gland histopathological findings, and two of the following features: abnormal Schirmer's test result, oral symptoms, or ocular symptoms. Thus they fulfilled the diagnostic criteria of the American-European Consensus Group for Sjögren's syndrome. ${ }^{11}$ After treatment, anti-SS-A/ SS-B antibody titres fell dramatically to within the normal range in all patients, salivary gland lymphocytic infiltration decreased in patients with follow up specimens ( 1 and 3), and sicca symptoms resolved in all patients.

To our knowledge, this is the first report to show beneficial therapeutic effects of IFN $\alpha$ on SSN. The mechanism whereby IFN $\alpha$ induced marked improvement in SSN as well as in Sjögren's syndrome itself in our patients is uncertain, but could be related to its immunomodulating effects. As IFN $\alpha$ caused neurological improvement in patients with two different forms of SSN, these two forms appear likely to share a common immunopathogenic mechanism responsive to IFN $\alpha$ treatment, irrespective of the specific form of SSN. However, as our three patients all had chronic, progressive relapsing neuropathies that responded to treatment with IVIG, IFN $\alpha$ effects might conceivably reflect IVIG responsive neuropathic mechanisms, even though Sjögren's syndrome itself did not respond to IVIG.

Trials of IFN $\alpha$ in a variety of forms of SSN are needed to determine whether IFN $\alpha$ therapy represents a first line treatment.

\section{Authors' affiliations}

S Yamada, K Mori, K Matsuo, A Inukai, G Sobue, Department of Neurology, Nagoya University Graduate School of Medicine, Nagoya, Japan

Y Kawagashira, Department of Neurology, Okazaki Municipal Hospital, Aichi, Japan

Competing interests: none declared

Correspondence to: Dr Gen Sobue, Department of Neurology, Nagoya University Graduate School of Medicine, 65 Tsurumai, Showa, Nagoya 466-8550, Japan; sobueg@med.nagoya-u.ac.jp

Received 15 July 2004

In revised form 4 August 2004

Accepted 5 August 2004

\section{REFERENCES}

1 Lafitte C, Amoura Z, Cacoub P, et al. Neurological complications of primary Sjögren's syndrome. J Neurol 2001;248:577-84.

2 Cummins MJ, Papas A, Kammer GM, et al. Treatment of primary Sjögren's syndrome with low-dose human interferon alfa administered by the oromucosal route: combined phase III results. Arthritis Rheum 2003;49:585-93.

3 Nobile-Orazio E, Baldini L, Barbieri S, et al. Treatment of patients with neuropathy and anti-MAG IgM M-proteins. Ann Neurol 1988;24:93-7.

4 Kapteyn TS, Bles W, Niiokiktiien CJ, et al. Standardization in platform stabilometry being a part of posturography. Agressologie 1983;24:321-6.

5 Mori K, Koike H, Misu K, et al. Spinal cord magnetic resonance imaging demonstrates sensory neuronal involvement and clinical severity in neuronopathy associated with Siögren's syndrome. I Neurol Neurosurg Psychiatry 2001;71:488-92.

6 Grant IA, Hunder GG, Homburger HA, et al. Peripheral neuropathy associated with sicca complex. Neurology 1997:48:855-62.

7 Greenspan JS, Daniels TE, Talal N, et al. The histopathology of Siögren's syndrome in labial salivary gland biopsies. Oral Surg Oral Med Oral Pathol 1974;37:217-29.

8 Griffin JW, Cornblath DR, Alexander E, et al. Ataxic sensory neuropathy and dorsal root ganglionitis associated with Siögren's syndrome. Ann Neurol 1990;27:304-15.

9 Takahashi Y, Takata T, Hoshino M, et al. Benefit of IVIG for long-standing ataxic sensory neuronopathy with Sjögren's syndrome. Neurology 2003;60:503-5.

10 Shiozawa S, Morimoto I, Tanaka Y, et al. A preliminary study on the interferon-alpha treatment for xerostomia of Sjögren's syndrome. $\mathrm{Br} J$ Rheumatol 1993;32:52-4.

11 Vitali C, Bombardieri S, Jonsson R, et al. Classification criteria for Siögren's syndrome: a revised version of European criteria proposed by the AmericanEuropean Consensus Group. Ann Rheum Dis 2002;61:554-8. 